\title{
Türkiye'de Sağlık Hizmetleri Talebinin Sayma Veri Modelleriyle İncelenmesi: İçsellik Sorunu
}

Canan GÜNEŞ, Department of Econometrics, Biga Faculty of Economics and Administrative Sciences, Canakkale Onsekiz Mart University, Turkey; e-mail: canangunes@comu.edu.tr

Mustafa $\ddot{\boldsymbol{U} N L} \ddot{\boldsymbol{U}}$, Department of Econometrics, Faculty of Economics and Administrative Sciences, Dokuz Eylul University, Turkey; e-mail: mustafaunlu88@gmail.com

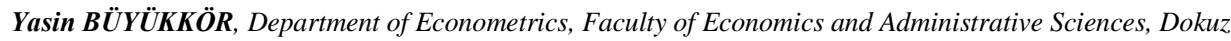
Eylul University, Turkey; e-mail: yasinbuyukkor@hotmail.com

Şenay ÜÇDOĞRUK BİRECIKLLI, Department of Econometrics, Faculty of Economics and Administrative Sciences, Dokuz Eylul University, Turkey; e-mail: s.ucdogruk@deu.edu.tr

\section{Investigation of Health Care Demand in Turkey by Count Data Models: Endogeneity Problem}

\begin{abstract}
Count data takes only integer values and it is the type of data that commonly used in econometric researches. The aim of this study is determining factors that effects health care demand in Turkey by using Turkish Statistical Institute's 2012 Health Survey data. Number of doctor visits variable which is taken into acount as an indicator of demand is a count data. It will be investigated that whether number of doctor visits which is one of the independent variables is endogenous or not. Instrumental Variable Method, Generalized Method of Moments and Zero Inflated Negative Binomial Model will be handled and political assessments will be made.
\end{abstract}

Keywords

Instrumental Variable Method, Generalized Method of Moments, Endogeneity, Health Care Demand, Count Data, Zero Inflated Negative Binomial Model.

JEL Classification Codes : $\quad$ C25, C26, I11.

$\ddot{\mathbf{O} z}$

Sayma verileri, sadece tam sayı değeri alır ve ekonometrik araştırmalarda sıkça kullanılan veri türlerinden biridir. Bu çalışmanın amacı, Türkiye'de sağlık hizmeti talebini etkileyen faktörleri Türkiye İstatistik Kurumu'nun 2012 yılı Sağlık Araştırmaları veri seti kullanılarak belirlemektir. Talebin göstergesi olarak seçilen doktora gitme sayısı, sayma verisi özelliği göstermektedir. Çalışmada bağımsız değişkenlerden biri olan sağlı durumunun içsel değişken olup olmadığı araştırılacaktır. Genelleştirilmiş Momentler Yöntemi, Alet Değişken Yöntemi ve Sıfır Değer Ağırlıklı Negatif Binom Modeli ile çalışılacak ve politik değerlendirilmelerde bulunulacaktır.

\section{Anahtar Sözcükler}

Alet Değişkenler Yöntemi, Genelleştirilmiş Momentler Yöntemi, İçsellik, Sağlık Hizmeti Talebi, Sayma Verileri, Sıfır Değer Ağırlıklı Negatif Binom Modeli. 
Güneş, C. \& M. Ünlü \& Y. Büyükkör \& Ş. Üçdoğruk Birecikli (2016), “Türkiye'de Sağlık Hizmetleri

Talebinin Sayma Veri Modelleriyle İncelenmesi: İçsellik Sorunu”, Sosyoekonomi, Vol. 24(30), 113-128.

\section{Giriş}

Sağlık hizmetleri devamlı olarak büyüyen ve ülkelerin gelişmişlik seviyelerine doğrudan etki eden önemli bir kavramdır. Gelişmiş ve gelişmekte olan ülkelerde sağlık hizmetlerine ayrılan kaynaklar, ülkelerin refah seviyeleri için kullanılan kaynakların büyük bir bölümünü oluşturmaktadır. Bu nedenle var olan kıt kaynakların etkin ve verimli bir şekilde kullanılması önem taşımaktadır.

Bireyler hasta olduklarında veya kaza geçirdiklerinde sağlık hizmetleri talebinde bulunmaktadır. Sağlık hizmetleri her birey tarafından talep edilmesinde oldukça yüksek olduğu için incelenmesi önem arz etmektedir. Sağlık hizmetlerine olan talep, sağlık hizmetlerinin fiyatları, bireylerin gelir ve eğitim düzeyleri, sağlık personelinin uzmanlığı, sağlık personelinin tutum ve davranışları, hizmeti talep eden bireylerin yaşı ve kilosu, sağlık kuruluşlarının fiziki altyapısı veya bireylerin alkol veya uyuşturucu bağımlılığı gibi birçok faktör tarafindan belirlenmektedir (Yaylalı vd, 2012: 564-565).

Literatürde sağlık hizmeti talebi üzerine gerçekleştirilmiş birçok çalışma bulunmaktadır. Gurmu (1997) çalışmasında doktora gitme ve hastaneye gitme sayılarını etkileyen etmenleri incelemiştir. Çocuk sayısı, yaş, gelir, medeni durum, cinsiyet, 1rk, eğitim gibi değişkenlerin açıklayıcı değişken olarak kullanıldığı çalışmada sağlık durumu değişkeninin önemli bir etken olduğu belirtilmiştir. Greene (2007) sağlık sigortasının, sağlık hizmeti talebini arttırdığını ortaya koymuştur. Winkelmann (2004), 1995-1999 yıllarında Almanya'da bireylerin doktora gitme sayısını kullanarak 1997 yılında gerçekleşen sağlık reformunu değerlendirmiştir. Reformun genel etkisinin doktora gitme sayısında \%10 azalmaya neden olduğu sonucuna ulaşmıştır. Malonzo \& Prantilla (2007), özel doktora ve kamu doktoruna gitme sayılarını kullanarak sağlık hizmeti talebini etkileyen etmenleri belirlemiştir. Özel doktora gitme sayısı; medeni durum, eğitim yılı, istihdam durumu, gelir, yaş, hastalık şikayetleri, genel sağlık ve hasta olup olmama durumlarından anlamlı olarak etkilenmektedir. Kamu doktoruna gitme sayısı ise sadece hastalık şikayetleri ve hasta olup olmama durumundan etkilenmektedir. Kung (2012) doktora gitme sayısı ile eğitim arasındaki ilişkiyi araştırdığı çalışmasında eğitim düzeyindeki artışın doktora gitmeyi azalttığı sonucuna ulaşmıştır.

Sağlık ekonomisi ve sağlık hizmetleri araştırmalarına ilişkin çalışmalar anket verilerine dayandığı için içsellik problemiyle sıkça karşılaşılmaktadır. Bu nedenle uygun modelin seçimi de zorlaşmaktadır (Hidayat \& Pokhrel, 2010: 10). Alet Değişken (IV) yöntemi içsellik sorununun üstesinden gelmek için kullanılan yöntemlerden biridir. Teorik ve uygulamalı literatürde IV'nin doğrusal regresyon modellerinde kullanımına geniş yer verilmiştir. Son yıllarda ise doğrusal olmayan regresyon modellerinin kullanımı yaygınlaşmaktadır. İçsel olması muhtemel iki durumlu bir değişken ile sayma veri modelleri tahmini uygulamalı iktisat literatüründe oldukça yaygındır. Mullahy (1997) içsel değişken iki durumlu olduğunda kullanılmak üzere doğrusal olmayan IV tahminini geliştirmiştir. Wooldridge (2014) ve Terza (2008) IV yönteminin uygulamasının kolay olmadığına, iki aşamalı tahmin yönteminin ilgilenilen durumun yapısal parametreleri için genellikle tutarlı olmadığına değinmiştir. Windmeijer \& Santos Silva (1997) çalışmasında, içsel açıklayıcı 
değişkenli sayma verisi modelleri için Genelleştirilmiş Momentler Yöntemi (GMM)'nin tutarlı tahminler verdiğini ortaya koymuştur.

Çalışmanın amacı, sağlık hizmeti talebi için uygun sayma verisi modelinin seçilmesi ve bireyin son dört hafta içerisinde pratisyen hekim, aile hekimi ya da uzman hekimden aldığı hizmetin sayısını etkileyen etmenlerin sağlık durumu açıklayıcı değişkeninin içselliğinin de dikkate alınarak belirlenmesidir.

Çalışma üç bölümden oluşmaktadır. Birinci bölümde sayma verilerinin genel yapısı, Poisson Regresyon Modeli (PRM), Negatif Binom Regresyon Modeli (NBRM) ve Sifir Değer Ağırlıklı Negatif Binom (ZINB) modelleri ile içsellik kavramı, IV ve GMM yöntemlerinin teorik yapıları ele alınarak bu modeller arasında seçim yapılmasını sağlayan spesifikasyon testleri incelenmiştir. İkinci bölümde sağlık hizmeti talebinin modellendiği ZINB, IV ve GMM sonuçları karşılaştırmalı olarak verilmiştir. Son bölümde ise sonuç ve öneriler yer almaktadır.

\section{Ekonometrik Yöntem}

Herhangi bir olayın belirlenen bir süreç içerisinde yapılan denemeler sonucunda meydana gelme sayısı, sayma verileri olarak ifade edilebilir. Sayma verisi söz konusu olduğunda parametre tahminleme yöntemi olarak En Küçük Kareler (EKK) yönteminin kullanılması, tutarsız ve etkin olmayan tahminlere yol açmaktadır. Bu sorunun üstesinden gelebilmek için çeşitli sayma verisi modelleri kullanılmaktadır (Long, 1997: 217).

Doktora gitme sayısı kesikli ve negatif olmayan değerler aldığından bu değişken için sayma verisi modelleri kullanılmaktadır. Genel sağlık durumu değişkeni, doktora gitme sayısının yerine kullanılabileceği için muhtemel içsel değişken olarak kullanılmıştır. Doktora gitme sayısı $y_{i}$; genel sağlık durumu $I_{i}$, dışsal değişken $x_{i}$ ve rassal hata terimi $u_{1 i}$ 'nin üstel bir fonksiyonu olmak üzere;

$$
y_{i}=\exp \left(I_{i} \alpha+x_{i} \beta\right)+u_{1 i}
$$

Burada üstel fonksiyon kullanılmasının amacı negatif olmamayı sağlamaktır. Denklem 1'de eğer $I_{i}$ ve $x_{i}$ dişsal değişkenler ise en yüksek olabilirlik (ML) yöntemi tutarlı ve etkin tahminler vermektedir. Ancak genel sağlık durumu, doktora gitme talebiyle beraber belirleniyor ise doktora gitme sayısı ve genel sağlık durumu eşanlı denklemler ile belirlenebilir.

Denklem 1'den yola çıkarak genel sağlık durumu, Denklem 2'deki gibi modellenir.

$$
I_{i}^{*}=\gamma z_{i}+x_{i} \beta+u_{2 i}
$$


Denklem 2'de $I_{i}^{*}$, genel sağlık durumunu; $z_{i}$ genel salık durumunu etkileyen ancak doktora gitme sayısını etkilemeyen ( $u_{1 i}$ ile ilişkisiz) gözlenebilen belirleyicilerin satır vektörüdür. Denklem 2, Denklem 1'de içsel olduğundan şüphelenilen değişkenin (genel sağlık durumu) indirgenmiş denklemidir.

Eğer genel sağlık durumu $I_{i}$ 'nin gözlenemeyen önemli bir belirleyicisi $u_{1 i}$ ile ilişkili ise Denklem 2'deki sapma artacaktır. Böyle durumlarda ML tahmini ( $I_{i}$ ile $u_{1 i}$ ilişkili ve $E\left(u_{1 i} \mid x_{i}\right) \neq 0$ ise) $\alpha$ 'yı sapmalı olarak tahmin edecektir. Ancak ML, açıklayıcı değişkenler dışsal ise etkin ve tutarlı tahminler vermektedir. Çalışmada, genel sağlık durumu değişkeninin içsel olduğu düşünüldüğü için IV ve GMM tahmin yöntemleri ile ilgilenilmektedir (Hidayat \& Pokhrel, 2010: 12).

\subsection{Sayma Verisi Modelleri}

Sayma verileri, ekonometrik araştırmalarda sıkça kullanılan veri türlerinden biridir. Sağlık kuruluşuna yapılan ziyaret sayısı [Munkin \& Trivedi (1999), Riphahn vd (2003), Contoyannis vd (2004)], alınan patent sayısı [Hausman vd (1984), Wang vd (1998)] ve piyasaya giren şirket sayısı [Asplund \& Sandin (1999)] gibi verilerin analizinde sayma verisi modelleri kullanılmaktadır. Bu modellerin yaygın olarak kullanıldığı alanlardan biri de sağlık hizmeti talebidir [Cameron \& Trivedi (1986), Cameron vd (1988), Pohlmeier \& Ulrich (1995), Deb \& Trivedi (1997), Gurmu (1997), Deb \& Holmes (2000)].

Bağımlı değişken sayma verisi olduğunda PRM, en sık kullanılan ve en basit yapıda olan modeldir. Bu model ile saymanın olasılı̆̆ Poisson dağılımı ile belirlenir ve koşullu ortalama ile koşullu varyans birbirine eşit olduğunda kullanılır Uygulamada ortalama ve varyansın birbirine eşit olduğu durumlar çok azdır. Genellikle varyans ortalamadan çok daha büyüktür. $\mathrm{Bu}$ durumda aşırı yayılım söz konusudur. Böylesi durumlarda parametre tahminleri, daha etkin olan NBRM ile yapılmaktadır (Cameron \& Trivedi, 1998: 71).

NBRM sıfırların olduğundan daha az tahminlenmesine neden olmaktadır. Sayma veri modellerinde örneklemdeki sıfır saymaların sayısı tahminden sonraki sıfırların sayısından fazla ise Sıfır Değer Ağırlıklı Poisson (ZIP) ve ZINB modelleri tercih edilmektedir. Bu modeller sıfırların ve pozitif saymaların birbirinden farklı süreçler yoluyla oluştuğunu varsaymaktadır. ZIP ve ZINB modelleri için genel yapı Denklem 3'de verilmiştir (Long, 1997: 244).

$$
E\left(y_{i} \mid x_{i}, z_{i}\right)=\left[0 \times \psi_{i}\right]+\left[\mu_{i} \times\left(1-\psi_{i}\right)\right]=\mu_{i}-\mu_{i} \psi_{i}
$$

Burada $\psi$ tahminlenecek olan bilinmeyen bir parametre olmak üzere; bir gözlem $\psi$ olasılıkla grup birde ve $1-\psi$ olasılıkla grup ikidedir. 


\section{2. İçsellik Kavramı}

Ekonometri literatüründe modeldeki gözlemlenen açıklayıcı değişkenlerin dışsal olması tercih edilmektedir. Bir modelde açıklayıcı içsel değişken(ler) belirli bir olasılık dağılımı ile belirlenmektedir. İçsellik sorunu modele dâhil edilmeyen değişken olması, değişkenlerdeki ölçme hataları ve eş anlılık durumlarında ortaya çıkmaktadır (Terza, 2008: 531).

Sayma verileri ile içsellik üzerine yapılan öncü çalışmaların sağlık ekonomisi konusunda yapıldığı görülmektedir (Hilbe, 2011: 416). Sağlı ekonomisinde yapılan çalışmalar "sağlık" veya "yaşam kalitesi" gibi gözlemlenemeyen yapıları içermektedir. Kronik hastalık ya da bireysel olarak ifade edilen sağlık durumu gibi gözlemlenen göstergelerden elde edilen bilgi, gizil yapıya örnek gösterilebilir. Gizil değişkenler ve onların gözlemlenen göstergeleri arasında ilişki olması içsellik problemine neden olacaktır (Jones \& O’Donnell, 2002: 2).

IV yöntemi, içsellik problemini çözmede sıkça kullanılan bir yöntemdir. Ancak IV tahmincileri, en küçük kareler ile kıyaslandığında önemli verimlilik kaybına yol açmaktadır. Mullahy (1997) gözlenemeyen değişkenlik, açıklayıcı değişkenlerle ilişkili olduğunda PRM tahmini için IV, GMM ve iki aşamalı tahmini önermiştir.

Literatürde iki durumlu bağımsız değişkenin içsel olduğu durumlar ile ilgili teorik çalışmalar da yer almaktadır. Model tahmini için gerekli olan katı varsayımların azaltıldığ yarı-parametrik süreçler geliştirilmiştir [Romeu \& Vera-Hernandez, 2005; Masuhara, 2008 v.b.]. Kozumi (2002) bu modellerin Bayesyen bir türünü analiz etmiştir. Staub (2009) sayma veri modellerinde iki durumlu bir değişkenden kaynaklanan içsellik ile ilgilenmiştir. İki durumlu içsel değişkenli sayma veri modelinde kullanılan dışsallık testlerinin performanslarını Monte Carlo simülasyonu ile karşılaş̧ırmıştır. Terza vd. (2008) doğrusal olmayan modellerde içsellik durumunda kullanılan iki aşamalı artık alma (two-stage residual inclusion) ve iki aşamalı tahminleyici değişimi (two-stage predictor substitution) IV yöntemlerini karşıllaştırmalı olarak incelemiştir. İki aşamalı artık alma tahminleyicisinin tutarlılığını ispatlamıştır.

Hidayat \& Pokhrel (2010) çalı̧̧masında içsel değişkenlerin olumsuz etkilerini ortadan kaldırmak için verilen istatistiksel ödünleri (yüksek standart hatalar, hassasiyet kaybı ve etkinlik kaybı) incelemiştir. Çalışmada iki tip sayma verisi modeli incelenmiştir. Bunlardan ilki kesikli bağımlı değişkene sahip ve ana denklemle karakterize edilen tiptir. $\mathrm{Bu}$ grupta PRM, ZINB ve Hurdle modelleri bulunmaktadır. İkinci tiptekiler ise ilk tiptekilerin özelliklerini genişleterek içsel değişkenleri de kapsayan IV ve GMM teknikleridir.

Son zamanlarda çok durumlu içsel değişkenler üzerine çalışmalar yapılmaktadır. Deb \& Trivedi (2006) tek bir eşitlik için simülasyon tabanlı NBRM ile tahminlemiştir. Çok değişkenli durum için genelleştirilmiş yöntemi Fabbri \& Monfardini (2011) önermiştir. 
Zimmer (2010)'de iki aşamalı bir süreç önermiştir. Geraci vd (2014) çok durumlu açıklayıcı değişkenler için iki aşamalı sürecin uygun olup olmadığını incelemiştir.

\subsection{Alet Değişkenler Yöntemi}

Doğrusal olmayan IV yöntemleri, hata terimi açıklayııı değişkenler ile korelasyonsuz olduğunda tutarlı tahminler vermektedir. Açıklayıcı değişken vektörü $\mathbf{x}$ ve alet değişken vektörü z olmak üzere IV tahminleyicisi Denklem 4'teki gibi tanımlanmaktadır.

$$
\hat{\beta}_{I V}=\left(\mathbf{z}^{\prime} \mathbf{x}\right)^{-1} \mathbf{z}^{\prime} \mathbf{y}
$$

$\mathbf{z}, \mathbf{x}$ ve $\mathbf{y}$ değişken vektörleri $N \times 1$ boyutludur. Bu tahminleyici $\mathbf{y}=\boldsymbol{\beta} \mathbf{x}+\mathbf{u}$ doğrusal modelinde $\boldsymbol{\beta}$ eğim katsayısının tutarlı bir tahminini vermektedir.

IV tahminleyicisinde açıklayıcı değişken sayısının, alet değişken sayısına eşit olması ideal bir durumdur. Aşırı belirlenme durumunda bazı alet değişkenler dışlanarak tam belirlenme sağlanır ve IV tahmini kullanılabilir. Ancak dışlanan alet değişkenler etkinlik kaybına yol açacaktır. Etkinlik kaybını önlemek için bir IV tahminleyicisi olan İki Aşamalı En Küçük Kareler (2SLS) kullanılabilir. Tam belirlenme durumunda 2SLS tahmini ile IV tahminleri aynı olacaktır. 2SLS tahminleyicisi Denklem 5 'te verilmiştir.

$$
\hat{\boldsymbol{\beta}}_{2 S L S}=\left[\mathbf{X}^{\prime} \mathbf{Z}\left(\mathbf{Z}^{\prime} \mathbf{Z}\right)^{-1} \mathbf{Z}^{\prime} \mathbf{X}\right]^{-1}\left[\mathbf{X}^{\prime} \mathbf{Z}\left(\mathbf{Z}^{\prime} \mathbf{Z}\right)^{-1} \mathbf{Z}^{\prime} \mathbf{y}\right]
$$

Farklı varyanslı hata terimlerinin olduğu ve aşırı belirlenme durumunda ise White (1982) 2SLS'den daha etkin sonuçlar veren iki aşamalı alet değişkenler (2SIV) tahminleyicisini önermiştir. $\mathbf{W}_{N}, r \times r$ boyutlu simetrik ağırlıklandırma matrisi olmak üzere $\mathbf{W}_{N}=\hat{\mathbf{S}}^{-1}$ şeklinde tanımlanmıştır. Farklı varyanslı hata terimleri için $\hat{\mathbf{S}}, 2 \mathrm{SLS}$ tahmininde olduğu gibi birinci aşamada elde edilen $\hat{\boldsymbol{\beta}}$ tahminine dayanarak hesaplanmaktadır.

$$
\hat{\mathbf{S}}=\frac{1}{N} \sum_{i=1}^{N} \hat{\mathbf{u}}_{\mathbf{i}}^{2} \mathbf{z}_{\mathbf{i}} \mathbf{z}_{\mathbf{i}}^{\prime}=\mathbf{Z}^{\prime} \mathbf{D Z} / \mathbf{N} \quad \hat{\mathbf{u}}_{\mathbf{i}}=\mathbf{y}_{\mathbf{i}}-\mathbf{x}_{\mathbf{i}}^{\prime} \hat{\boldsymbol{\beta}}_{2 S L S}
$$

2SIV tahminleyicisi Denklem 7'de tanımlanmıştır.

$$
\hat{\boldsymbol{\beta}}_{2 S I V}=\left[\left(\mathbf{X}^{\prime} \mathbf{Z}\right) \hat{\mathbf{S}}^{-1}\left(\mathbf{Z}^{\prime} \mathbf{X}\right)\right]^{-1}\left(\mathbf{X}^{\prime} \mathbf{Z}\right) \hat{\mathbf{S}}^{-1}\left(\mathbf{Z}^{\prime} \mathbf{y}\right)
$$

İçsel açıklayıcı değişkenin iki durumlu yapısı göz ardı edilerek doğrusal 2SLS ya da 2SIV ile model tahmin edilebilir. Uygun doğrusal olmayan regresyondan, içsel açıklayıcı 
değişken için tahmin değerleri elde edilir. Daha sonra sayma modeli için alet değişken olarak bu tahmin değerleri kullanılarak doğrusal IV uygulanır (Cameron \& Trivedi, 2005: 187193).

\subsection{Genelleştirilmiş Momentler Yöntemi}

$i=1, \ldots, N$ için $y_{i}$ bağımsız Poisson dağılımına sahip bağımlı sayma değişkeni olmak üzere, koşullu ortalaması Denklem 8'deki gibi tanımlanmıştır.

$$
E\left(y_{i} \mid x_{i}\right)=\mu_{i}=\exp \left(\mathbf{x}_{i}^{\prime} \boldsymbol{\beta}\right)
$$

Denklem 8 ile belirtilen koşullu ortalama, dolaylı olarak aşağıdaki regresyon modelini tanımlar:

$$
\mathbf{y}_{i}=\boldsymbol{\mu}_{i}+\mathbf{u}_{i}=\exp \left(\mathbf{x}_{i}^{T} \boldsymbol{\beta}\right)+u_{i}
$$

Denklem 9'da $E\left(u_{i} \mid x_{i}\right)=0$ 'dır. GMM tahmini, bu moment koşuluna dayanmaktadır ve

$$
(\mathbf{y}-\boldsymbol{\mu})^{T} \mathbf{X} \mathbf{W}_{N}^{-1} \mathbf{X}(\mathbf{y}-\boldsymbol{\mu})
$$

ifadesini minimize eder. Burada WN ağırlık matrisidir. Denklem $10, \mathbf{X}^{T}(\mathbf{y}-\boldsymbol{\mu})=0$ noktasında minimum değeri almaktadır.

$x_{i}$ vektörü içsel değişken içerdiğinde,

$$
E\left(u_{i} \mid x_{i}\right) \neq 0
$$

olur. $\mathrm{Bu}$ durumda $\mu_{i}$ artık $y_{i}$ 'nin koşullu ortalaması değildir. Eğer Denklem 12'deki koşulu sağlayan $z_{i}$ alet değişkenleri mevcutsa

$$
E\left(u_{i} \mid z_{i}\right)=0
$$

doğrusal olmayan alet değişken tahminleyicisi aşağıdaki ifadenin minimizasyonu ile elde edilir.

$$
(\mathbf{y}-\boldsymbol{\mu})^{T} \mathbf{Z}\left(\mathbf{Z}^{T} \mathbf{Z}\right)^{-1} \mathbf{Z}^{T}(\mathbf{y}-\boldsymbol{\mu})
$$


Elde edilen bu ifade tek aşamalı GMM tahminleyicisidir. Alet değişkenler belirlendiğinde, etkin iki aşamalı GMM tahminleyicisi

$$
(\mathbf{y}-\boldsymbol{\mu})^{T} \mathbf{Z}\left(\mathbf{Z}^{T} \mathbf{\Omega Z}\right)^{-1} \mathbf{Z}^{T}(\mathbf{y}-\boldsymbol{\mu})
$$

ifadesinin minimize edilmesiyle elde edilir.

$$
\operatorname{Burada}\left(\mathbf{Z}^{T} \mathbf{\Omega Z}\right)=\sum_{i=1}^{N}\left(y_{i}-\tilde{\mu}_{i}\right)^{2} \mathbf{z}_{i} \mathbf{z}_{i}^{T} \text { ifadesi, } \tilde{\mu}_{i}=\exp \left(\mathbf{x}_{i}^{T} \tilde{\boldsymbol{\beta}}\right) \text { ve } \tilde{\boldsymbol{\beta}} \text { da } \beta \text { 'nın ilk }
$$

aşama tahmini olmak üzere $\mathbf{Z}^{T}(\mathbf{y}-\boldsymbol{\mu})$ 'nin asimptotik varyans tahminidir. $\Omega$ ise kuadratik formun tanım matirisidir.

İki aşamalı GMM tahminleyicisinin varyansını minimum yapan en uygun alet değişkenler $Z^{*}=E\left(\mathbf{\Omega}^{-1} \mathbf{D} \mid \mathbf{Z}\right)$ ile elde edilir. Burada $\mathrm{D}$ matrisi $\partial(y-\mu) / \partial \beta$ türevlerine eşittir. Böylece en uygun alet değiş̧kenler $Z^{*}=E\left(\mathbf{\Omega}^{-1} \mathbf{M X} \mid \mathbf{Z}\right)$ ile elde edilebilir (Windmeijer \& Santos-Silva, 1997: 282-284).

\subsection{Spesifikasyon Testleri}

Bağımlı değişken sayma verisi iken ve iki durumlu içsel açıklayıcı değişken söz konusu olduğunda doğru modelin spesifikasyonu için birçok test kullanılabilir. Grafik 1 'de genel olarak hangi testlerin uygulanabileceği ve modelin varsayımlarıyla ilişkileri gösterilmiştir.

Modelde içsellik varsayımı Hausman spesifikasyon testiyle belirlenir (Wu- Hausman ve Durbin-Wu-Hausman veya DWH). Eğer ML ile GMM veya IV katsayı tahminleri arasında anlamlı bir farklılık varsa, değişkenin dışsal olduğunu belirten $H_{0}$ hipotezi reddedilir. Bu durumda GMM veya IV tercih edilir. Bu aşamadan sonra değişen varyansın test edilmesi gerekmektedir. Eğer modelde değişen varyans mevcutsa, IV tahminleri tutarsız olur ve doğrusal IV yerine GMM tercih edilir.

Alet değişkenlerin tanımlanması için çeşitli testler uygulanmaktadır. Bu testler: alet değişkenlerin içsel değişkenle olan ilişkisinin gücü ve hata terimiyle ortogonal olması için uygulanan testlerdir. Alet değişkenlerle ilgili olarak diğer bir test ise geçerlilik testidir. Alet değişkenler aşırı belirlenmeye karşı test edilir. Hansen J (1982) ve Sargan (1975) istatistikleri sırasıyla GMM ve IV için kullanılabilir (Hidayat \& Pokhrel, 2010: 14).

Alet değişkenlerin tanımlanması için çeşitli testler uygulanmaktadır. Bu testler: alet değişkenlerin içsel değişkenle olan ilişkisinin gücü ve hata terimiyle ortogonal olması için uygulanan testlerdir. Alet değişkenlerle ilgili olarak diğer bir test ise geçerlilik testidir. Alet 
değişkenler aşırı belirlenmeye karşı test edilir. Hansen J (1982) ve Sargan (1975) istatistikleri sırasıyla GMM ve IV için kullanılabilir (Hidayat \& Pokhrel, 2010: 14).

Grafik: 1

\section{Spesifikasyon Testleri}

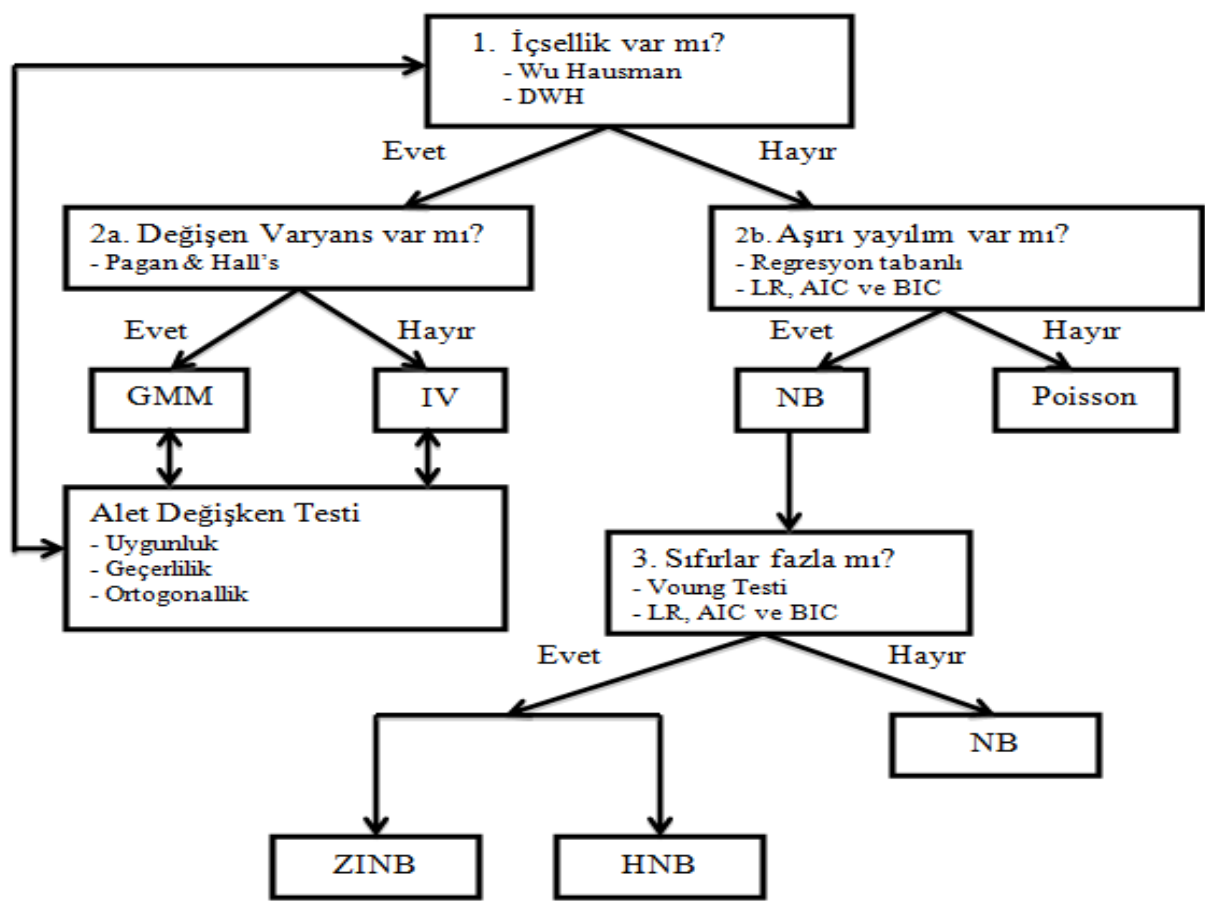

Kaynak: Hidayat \& Pokhrel, 2010: 15.

İçsellik durumunun araştırıldığı hipotez reddedilirse, bilinen sayma veri modelleri kullanılır. Bu modeller aşırı yayılım ve sıfır değer ağırlıklı modeller olarak belirlenebilir. Eğer verilerde aşırı yayılım yoksa PRM, aşırı yayılım varsa NBRM kullanılır. Bu iki model arasında seçim yapabilmek için sıkça kullanılan seçim kriterlerinden Akaike Bilgi Kriteri (AIC) veya Bayesyen Bilgi Kriteri (BIC) kullanılır. Eğer verilerde sıfır yoğunluğu fazla ise Voung istatistiği NB ve ZINB arasında seçim yapmayı sağlar. Voung istatistiği standart normal dağılıma sahiptir ve büyük pozitif değerleri ZINB' yi, büyük negatif değerleri ise NB modelini tercih etmeye yönlendirir (Hidayat \& Pokhrel, 2010: 14-16).

\section{Veri Seti ve Bulgular}

TUİK tarafindan 2008 yılından itibaren iki yılda bir gerçekleştirilen Sağlık Araştırması ile bebek, çocuk ve yetişkinlerin sağlık durumları hakkında bilgi toplanmaktadır. Çalışmada kullanılan veri seti 2012 yılı Sağlık Araştırması Anketi verileridir. 15 yaş ve üzerinde toplam 12,700 yetişkin birey ile çalışılmıştır. Modellerde 
kullanılan bağımlı değişken, bireylere yapılan anketten önceki dört hafta içerisinde pratisyen, aile hekimi ya da uzman hekimden kaç kez hizmet alındığını gösteren sayma verisidir. Bu değişkene ait frekans yapısı Tablo 1'de verilmiştir.

Tablo: 1

Doktora Gitme Sayısı Değişkeni

\begin{tabular}{|l|c|c|}
\hline Doktora Gitme Sayısı & Frekans & Yüzde (\%) \\
\hline 0 & 8,288 & 65.26 \\
\hline 1 & 2,347 & 18.48 \\
\hline 2 & 1,146 & 9.02 \\
\hline 3 & 400 & 3.15 \\
\hline 4 & 221 & 0.74 \\
\hline 5 & 106 & 0.57 \\
\hline 6 & 72 & 0.26 \\
\hline 7 & 33 & 0.24 \\
\hline 8 & 31 & 0.07 \\
\hline 9 & 9 & 0.11 \\
\hline 10 & 14 & 0.26 \\
\hline 11 ve üzeri & 33 & \\
\hline
\end{tabular}

Tablo 1'deki sonuçlara göre, ankete katılan kişilerin \%65'i son 4 hafta içerisinde hiç doktora gitmezken, 11 ve üzeri sayıda doktora gidenlerin oranı $\% 0.26$ 'dır. Modelde kullanılan bağımsız değişkenlere ait tanımlayıcı istatistikler Tablo 2'de verilmiştir.

Veri setinde yer alan bireylerin \%53'ü kadınlardan, geriye kalan \%47'si de erkeklerden oluşmaktadır. Ankete katılan kişiler arasında en çok yataklı tedavi alınan yaş aralığının 25-34 yaş aralığı olduğu ve ilerleyen yaşlarda yataklı tedavi alanların sayısının azaldığ1 görülmektedir. Eğitim düzeyi açısından bakıldığında çoğunluğun ilkokul mezunu olduğu görülmektedir. Son bir hafta içerisinde ayni veya nakdi bir gelir elde etmek amacıyla bir saat bile olsa bir işte çalışma durumunu gösteren çalışma durumu değişkenine göre ankete katılanların yaklaşık \%61'i çalışmamaktadır. Çalışma ve Sosyal Güvenlik Bakanlığ İstatistik Dairesi tarafından elde edilen verilere göre 2012 yılında 16 yaşını doldurmuş işçiler için net asgari ücret 739.79 TL'dir. Bu nedenle hanenin aylık net geliri için veri setinin gelir sınıflamasına uygun olarak alt sınır 750 TL olarak seçilmiştir. TUİK'in gelir sınıflamasında en üst sınıf 2,301 TL ve üzeri olduğu için, çalışmanın gelir değişkeninin üst sınırı da bu şekilde belirlenmiştir. Veri setindeki bireylerin yaklaşık \% 17 'sinin hane geliri asgari ücretin altındadır. Diğer bir değişken olan vücut kitle endeksi (vki), bireylerin ağırlıklarının (kg), boy uzunluklarının (m) karesine oranlanmasıyla elde edilmiştir.

Bağımlı değişken olan doktora gitme sayısının ortalaması 0.7002 ve varyansı 1.4681 'dir. Varyans, ortalamadan büyük olduğu için aşırı yayılım durumu söz konusudur. Doktora gitme sayısının \%65.26'sı sıfırlardan oluştuğu için ZIP veya ZINB modellerinin tercih edilmesi uygun bir yaklaşımdır. Ayrıca Vuong istatistiğine bakıldığında, istatistik değerinin pozitif ve büyük (6.134) olması, ZINB'nin tercih edilmesini gerektirmektedir (Desmaris \& Harden, 2013: 813). 
Tablo: 2

Tanımlayıcı İstatistikler

\begin{tabular}{|c|c|c|c|c|}
\hline Değişkenler & Ortalama & $\begin{array}{c}\text { Std } \\
\text { Sapma }\end{array}$ & Min. & Max. \\
\hline Doktora gitme sayıst & 0.7002 & 1.4681 & 0 & 35 \\
\hline \multicolumn{5}{|l|}{ Genel sağlık durumu(kötü) } \\
\hline Kötü & 0.7150 & 0.4515 & 0 & 1 \\
\hline İyi & 0.2850 & 0.4515 & 0 & 1 \\
\hline \multicolumn{5}{|l|}{ Cinsiyet(kadın) } \\
\hline Kadin & 0.5321 & 0.4990 & 0 & 1 \\
\hline Erkek & 0.4679 & 0.4990 & 0 & 1 \\
\hline \multicolumn{5}{|l|}{ Medeni durum(bekar) } \\
\hline Bekar & 0.3072 & 0.4613 & 0 & 1 \\
\hline Evli & 0.6928 & 0.4613 & 0 & 1 \\
\hline \multicolumn{5}{|l|}{ **Yataklı tedavi alan bireyin yaş sınıfi } \\
\hline $15-24 *$ yataklı tedavi alma durumu & 0.0091 & 0.0948 & 0 & 1 \\
\hline $25-34 *$ yataklı tedavi alma durumu & 0.0173 & 0.1306 & 0 & 1 \\
\hline $35-44 *$ yataklı tedavi alma durumu & 0.0132 & 0.1140 & 0 & 1 \\
\hline 45-54*yataklı tedavi alma durumu & 0.0131 & 0.1137 & 0 & 1 \\
\hline 55-64*yataklı tedavi alma durumu & 0.0114 & 0.1060 & 0 & 1 \\
\hline 65-74*yataklı tedavi alma durumu & 0.0112 & 0.1052 & 0 & 1 \\
\hline 75 ve üzeri*yataklı tedavi alma durumu & 0.0065 & 0.0806 & 0 & 1 \\
\hline \multicolumn{5}{|l|}{ Ĕ̈itim düzeyi(bir okul bitirmemiş) } \\
\hline Bir okul bitirmemiş & 0.1165 & 0.3209 & 0 & 1 \\
\hline İlkokul & 0.3545 & 0.4784 & 0 & 1 \\
\hline Ortaokul & 0.1910 & 0.3931 & 0 & 1 \\
\hline Lise & 0.1983 & 0.3988 & 0 & 1 \\
\hline Yükseköğretim & 0.1396 & 0.3466 & 0 & 1 \\
\hline \multicolumn{5}{|l|}{ Çalıșma durumu(Çalıșmıyor) } \\
\hline Çalışmıyor & 0.6055 & 0.4888 & 0 & 1 \\
\hline Çalışıyor & 0.3945 & 0.4888 & 0 & 1 \\
\hline \multicolumn{5}{|c|}{ Hanenin Aylık Net Gelir Düzeyi(2301 TL'den fazla) } \\
\hline 750 TL'den az & 0.1656 & 0.3717 & 0 & 1 \\
\hline $751-2300 \mathrm{TL}$ & 0.6221 & 0.4849 & 0 & 1 \\
\hline 2301 TL'den fazla & 0.2123 & 0.4089 & 0 & 1 \\
\hline \multicolumn{5}{|c|}{$\begin{array}{l}\text { ***Son } 6 \text { ay içinde herhangi bir sağlık problemi nedeniyle günlük } \\
\text { yaşam faaliyetlerinin kıstlanma durumu(1:3) }\end{array}$} \\
\hline Kisitlanmadi & 0.7054 & 0.2863 & 0 & 1 \\
\hline Kisitland1 & 0.2045 & 0.4033 & 0 & 1 \\
\hline Ciddi Kisıtlandı & 0.0901 & 0.4559 & 0 & 1 \\
\hline \multicolumn{5}{|c|}{$\begin{array}{l}\text { ***Son } 12 \text { ay içerisinde birinci basamak sağllk kuruluşlarından } \\
\text { kronik hastalıkları izlemi koruyucu sağlık hizmeti alma durumu }\end{array}$} \\
\hline Almadı & 0.8908 & 0.3119 & 0 & 1 \\
\hline Ald 1 & 0.1092 & 0.3119 & 0 & 1 \\
\hline ***Vücut kitle endeksi & 25.9990 & 4.9140 & 14.0625 & 54.0779 \\
\hline
\end{tabular}

Temel sinıflar parantez içerisinde belirtilmiştir.

**Etkileşim değişkeni kişinin yaş grubu ile yataklı tedavi alıp almama durumunun çarpılmasıyla elde edilmiştir.

***Să̆lık durumu yerine kullanılan alet de ğişkenler.

$\mathrm{Bu}$ çalışmada kullanılan dışsal değişkenler; cinsiyet, medeni durum, yataklı tedavi alan kişinin yaşı, eğitim durumu, hanenin net geliri ve çalışma durumu değişkenleridir. Bir diğer açıklayıcı değişken olan genel sağlık durumunun ise içsel olduğu düşünülmektedir (Windmeijer \& Santos-Silva, 1997: 288). Bireyin sağlık sigortası sahibi olma durumu sağlık 
hizmeti talebini etkileyen önemli faktörlerden birisidir. Ancak sağlık sigortası sahipliği içsel olmasından şüphelenilen bir diğer açıklayıcı değişkendir. Bu nedenle sağlık sigortası sahipliği durumu modellere dâhil edilmemiş, içsel olduğu düşünülen tek değişken ile çalışılmıştır.

Bireyin genel sağlık durumunun iyi ve kötü olup olmadığını gösteren değişken iki durumlu bir değişkendir. Genel sağlık durumu değişkenin yerine kullanılan alet değişkenler; son 6 ay içinde herhangi bir sağlık problemi nedeniyle günlük yaşam faaliyetlerinin kısıtlanma durumu, son 12 ay içerisinde birinci basamak sağlık kuruluşlarından kronik hastalıklarla ilgili koruyucu sağlık hizmeti alma durumu, vücut kitle endeksi olarak seçilmiştir.

Öncelikle bireyin genel sağlık durumunun içsel olup olmadığını araştırmak amacıyla Denklem 1'deki model kullanılarak Wu-Hausman F ve Durbin-Wu-Hausman $\chi^{2}$ testi yapılmıştır. Sonuçlar Tablo 3 'te yer almaktadır. Değişkenin dışsal olduğunu söyleyen sıfır hipotezi reddedilmiştir ve bireyin sağlık durumunun içsel olduğuna karar verilmiştir. $\mathrm{Bu}$ nedenle ML tahminleri etkin ve tutarlı tahminler vermeyeceği için IV veya GMM kullanılması uygun olacaktır.

Tablo: 3

Sağlık Durumunun İçsellik Testi

\begin{tabular}{|l|c|c|}
\hline İcsellik Testi & İstatistik & Prob Değeri \\
\hline Wu-Hausman F testi & $\mathrm{F}(1,12664)=165.8209$ & 0.0000 \\
\hline Durbin-Wu-Hausman $\chi^{2}$ testi & $\chi^{2}(1)=163.9233$ & 0.0000 \\
\hline
\end{tabular}

Diğer bir adımda belirlenen alet değişkenler son 6 ay içinde herhangi bir sağlık problemi nedeniyle günlük yaşam faaliyetlerinin kısıtlanma durumu, son 12 ay içerisinde birinci basamak sağlık kuruluşlarından kronik hastalıklarla ilgili koruyucu sağlık hizmeti alma durumu, vücut kitle endeksinin hata terimiyle ilişkisiz olup olmadığının test edilmesi gerekmektedir. Bu nedenle IV yöntemi için Sargan Testi (1975) ve GMM yöntemi için Hansen J (1982) testi yapılmıştır. Yapılan her iki testte de seçilen alet değişkenlerin hata terimiyle ilişkisiz olduğunu söyleyen sıfır hipotezi reddedilememiştir. Bunun sonucunda söz konusu alet değişkenlerin uygun olduğuna karar verilmiştir (Tablo 4).

Tablo: 4

Alet Değișkenlerin Geçerlilik Testleri

\begin{tabular}{|l|c|c|}
\hline Geçerlilik Testi & Ístatistik & Prob Değeri \\
\hline Sargan istatistiği & $\chi^{2}(2)=0.647$ & 0.7234 \\
\hline Hansen J istatistiği & $\chi^{2}(2)=0.4858$ & 0.7843 \\
\hline
\end{tabular}

Son olarak IV yönteminde değişen varyans olup olmadığını belirlemek amacıyla Pagan-Hall (1983) testi yapılmış ve modelin eş varyanslı olduğunu söyleyen sıfır hipotezi 
reddedilmiştir. Bu sonuç IV yerine GMM'nin kullanılmasının daha uygun olduğunu göstermektedir (Tablo 5).

\section{Tablo: 5}

\section{Modeli İçin Değişen Varyans Testi}

\begin{tabular}{|l|c|c|}
\hline Değişen Varyans Testi & İstatistik & Prob Değeri \\
\hline Pagan-Hall testi & $\chi^{2}(2)=156.830$ & 0.0000 \\
\hline
\end{tabular}

Tablo 6'da değişkenlere ait ZINB, IV ve GMM sonuçları yer almaktadır. Genel olarak bakıldığında sağlık durumu değişkeninin içselliğinin dikkate alınmadığı ZINB'den farklı olarak; içselliğin dikkate alınarak elde edilen IV ve GMM modellerinde cinsiyet, eğitim ve gelir değişkenlerine ilişkin katsayıların anlamlı olduğu görülmektedir. Tüm modellerde katsayıların işaretleri benzerlik göstermektedir. Ayrıca IV ve GMM sonuçlarına göre sağlık durumu değişkeninin katsayıları ZINB katsayısından yaklaşık üç kat daha yüksek çıkmıştır. Windmeijer \& Santos Silva (1997) çalışmalarında sağlık durumunun kötü olması durumunda doktora gitme sayısının arttığını ortaya koyarken, Tablo 6'da yer alan model sonuçlarına göre genel sağlık durumu iyi olan bireylerin \%156 olasılıkla daha fazla doktora gittikleri görülmektedir.

Tablo: 6

ZINB, IV ve GMM Model Tahmin Sonuçları

\begin{tabular}{|c|c|c|c|c|c|c|}
\hline \multirow{2}{*}{$\begin{array}{l}\text { Bağımlı değiş̧ken: Doktora gitme sayısı } \\
\text { Değişkenler }\end{array}$} & \multicolumn{2}{|c|}{ ZINB } & \multicolumn{2}{|c|}{ IV } & \multicolumn{2}{|c|}{ GMM } \\
\hline & Katsayısı & Std. Hata & Katsayısı & Std. Hata & Katsayısı & Std. Hata \\
\hline \multicolumn{7}{|l|}{ Genel sağlık durumu (kötü) } \\
\hline İyi & $0.4739 * * *$ & 0.0499 & $1.5688 * * *$ & 0.0843 & $1.5643 * * *$ & 0.1167 \\
\hline \multicolumn{7}{|l|}{ Cinsiyet (kadin) } \\
\hline Erkek & -0.0737 & 0.0485 & $-0.0810^{* * *}$ & 0.0293 & $-0.0824 * * *$ & 0.0307 \\
\hline \multicolumn{7}{|l|}{ Medeni durum (bekar) } \\
\hline Evli & $0.1826 * * *$ & 0.0479 & $0.0934 * * *$ & 0.0309 & $0.0951 * * *$ & 0.0312 \\
\hline \multicolumn{7}{|l|}{ Yataklı tedavi alan bireyin yaș sınıfi } \\
\hline $15-24 *$ yataklı tedavi alma durumu & $0.5149 * * *$ & 0.1395 & $0.6127 * * *$ & 0.1379 & $0.6047 * * *$ & 0.2256 \\
\hline $25-34 *$ yataklı tedavi alma durumu & $0.6074 * * *$ & 0.1227 & $0.5407 * * *$ & 0.1001 & $0.5343 * * *$ & 0.1584 \\
\hline $35-44 *$ yataklı tedavi alma durumu & $0.3741 * * *$ & 0.1316 & $0.3340 * * *$ & 0.1152 & $0.3338^{* *}$ & 0.1584 \\
\hline $45-54 *$ yataklı tedavi alma durumu & $0.6177 * * *$ & 0.1190 & $0.5114 * * *$ & 0.1170 & $0.5474 * *$ & 0.2317 \\
\hline 55-64 *yataklı tedavi alma durumu & $0.4299 * * *$ & 0.1194 & $0.2304 *$ & 0.1276 & 0.2215 & 0.2024 \\
\hline $65-74 *$ yataklı tedavi alma durumu & $0.3755^{* * *}$ & 0.1206 & 0.1680 & 0.1300 & 0.1729 & 0.1824 \\
\hline 75 ve üzeri*yataklı tedavi alma durumu & $0.7418^{* * *}$ & 0.1463 & $0.9031 * * *$ & 0.1660 & $0.8963 * *$ & 0.3466 \\
\hline \multicolumn{7}{|l|}{ Ĕgitim düzeyi (bir okul bitirmemiş) } \\
\hline İlkokul & 0.0212 & 0.0578 & $0.1691 * * *$ & 0.0473 & $0.1672 * * *$ & 0.0541 \\
\hline Ortaokul & 0.1014 & 0.0750 & $0.3903 * * *$ & 0.0581 & $0.3906^{* * *}$ & 0.0691 \\
\hline Lise & -0.1055 & 0.0748 & $0.2338 * * *$ & 0.0572 & $0.2318^{* * *}$ & 0.0692 \\
\hline Yükseköğretim & -0.0022 & 0.0922 & $0.3335 * * *$ & 0.0645 & $0.3305^{* * *}$ & 0.0323 \\
\hline \multicolumn{7}{|l|}{ Çalışma durumu (Çalışmıyor) } \\
\hline Çalışıyor & $-0.2520 * * *$ & 0.0547 & $-0.1357 * * *$ & 0.0322 & $-0.1349 * * *$ & 0.0323 \\
\hline \multicolumn{7}{|l|}{$\begin{array}{l}\text { Hanenin Aylık Net Gelir Düzeyi } \\
\text { (2301 TL'den fazla) }\end{array}$} \\
\hline 750 TL'den az & -0.0025 & 0.0746 & $-0.0784 *$ & 0.0472 & $-0.0795 *$ & 0.0477 \\
\hline $751-2300 \mathrm{TL}$ & $-0.1178 * *$ & 0.0570 & $-0.0637 *$ & 0.0357 & $-0.0627 *$ & 0.0332 \\
\hline Sabit & $-0.3255 * * *$ & 0.0907 & 0.0685 & 0.0702 & 0.0700 & 0.0799 \\
\hline
\end{tabular}

Not: ***\%1'de, **\%5'de, *\%10'da istatistiksel olarak anlamll. 
Cinsiyet değişkeni incelendiğinde erkeklerin doktora gitme olasılıklarının \%8 daha az olduğu görülmüştür. Bireylerin evli olması doktora gitme sayıları üzerinde pozitif etki yaratmaktadır. Modele önce yaş sınıfları konmuş ancak sonuçlar beklentilere uygun çıkmamıştır. Geçmiş çalışmalar incelendiğinde bireyin yaşı arttıkça daha çok sağlık hizmeti aldığı görülmüştür. Bu nedenle yaş gruplarıyla yataklı tedavi alma durumundan bir etkileşim değişkeni oluşturulmuştur. Burada yataklı tedavi alan düşük yaş gruplarında sağlık hizmetinin arttığı, daha sonraki yaş gruplarında sağlık hizmeti alma durumunun değişkenlik gösterdiği ve son olarak yataklı tedavi alan yaşlıların daha fazla sağlık hizmeti aldıkları görülmüştür. Eğitim düzeyi incelendiğinde, bir okul bitirmemişlere göre diğer eğitim düzeylerinde doktora gitme sayıları daha yüksektir. Çalışan bireylerin daha az doktora gittiği görülmektedir. Hanenin aylık net geliri incelendiğinde, yüksek gelir düzeyindeki bireylere göre düşük gelir seviyesine sahip bireyler daha az doktora gitmektedir.

\section{Sonuç ve Öneriler}

Toplumların refah seviyelerinin göstergelerinden biri olan sağlık hizmetlerinin önemi günümüzde ön plana çıkmaktadır. Sağlık ekonomisi ve sağlık hizmetleri için geliştirilen politikaların belirlenmesinde sağlık kurumlarının özellikleri kadar, hizmet alan bireylerin sosyo-demografik ve ekonomik özellikleri de önemlidir.2012 yılı Sağlık Araştırması verileri kullanılarak elde edilen modeller birlikte değerlendirildiğinde içselliğin dikkate alınması, katsayı tahminlerinin anlamlılıklarını olumlu yönde etkilemiştir. Belirtilen yapıda olan ve birbirine benzer sonuçlar veren IV ve GMM modelleri arasından değişen varyans durumunda daha tutarlı sonuçlar veren GMM modelinin tercih edilmesi gerektiği görülmüştür (Tablo 6).

İçsel olan sağlık durumu değişkenine ait sonuçlar incelendiğinde, literatürün aksine sağlık durumunu iyi olarak belirten bireylerin kötü olarak belirtenlere göre daha çok doktora gittikleri sonucuna ulaşılmıştır.

Sağlık hizmeti talebini belirleyen önemli faktörlerden biri de bireyin sigortalı olma durumudur. Türkiye gelişmekte olan bir ülke olması nedeniyle sağlık hizmetleri konusunda sıkça reformlar yapmaktadır. 2012 yılından itibaren uygulanmakta olan Genel Sağlık Sigortası (GSS)'nın sağlık hizmeti talebi üzerine etkisi bu çalışmanın kapsamı dışında bırakılmıştır. Sonraki çalışmalarda sigortalı olma durumunun doktora gitme sayısı üzerine etkisi incelenebilir. Ayrıca TÜİK tarafından henüz yayınlanmamış olan 2014 yılı Sağlık Araştırması verileri kullanılarak GSS'nin sağlık hizmeti talebi üzerine etkileri de 2012 yılı verileriyle karşılaştırmalı olarak analiz edilebilir.

\section{Kaynaklar}

Asplund, M. \& R. Sandin (1999), "The Number of Firms and Production Capacity in Relation to Market Size”, Journal of Industrial Economics, 47(1), 69-85.

Cameron, A.C. \& P.K. Trivedi (1986), "Econometric Models Based on Count Data: Comparisons and Applications of Some Estimators and Tests", Journal of Applied Econometrics, 1, 29-54. 
Cameron, A.C. \& P.K. Trivedi \& F. Milne \& J. Piggott (1988), “A Microeconometric Model of the Demand for Health Care and Health Insurance in Australia", Review of Economic Studies, 55, 85-106.

Cameron, A.C. \& P.K. Trivedi (1998), Regression Analysis of Count Data, New York: Cambridge University Press.

Cameron, A.C. \& P.K. Trivedi (2005), Microeconometrics Methods and Applications, New York: Cambridge University Press.

Contoyannis, C. \& A. Jones \& N. Rice (2004), “The Dynamics of Health in the British Household Panel Survey", Journal of Applied Econometrics, 19(4), 473-503.

Deb, P. \& A.M. Holmes (2000), "Estimates of Use and Costs of Behavioural Health Care: A Comparison of Standard and Finite Mixture Models“, Health Economics, 9(6), 475-489.

Deb, P. \& P.K. Trivedi (1997), "Demand for Medical Care by the Elderly: A Finite Mixture Approach", Journal of Applied Econometrics, 12, 313-336.

Deb, P. \& P.K. Trivedi (2006), "Specification and Simulated Likelihood Estimation of a NonNormal Treatment-Outcome Model with Selection: Application to Health Care Utilization”, Econometrics Journal, 9(2), 307-331.

Desmaris, B.A. \& J.J. Harden (2013), "Testing for Zero Inflation in Count Models: Bias Correction fort he Vuong Test", The Stata Journal, 13(4), 810-835.

Geraci, A. \& D. Fabbri \& C. Monfardini (2014), "Testing Exogeneity of Multinomial Regressors in Count Data Models: Does Two Stage Residual Inclusion Work?", Quaderni-Working Papers DSE, No. 921.

Greene, W. (2007), "Functional Forms for the Negative Binomial Model for Count Data", Economic Letters, 99, 585-590.

Gurmu, S. (1997), "Semi-Parametric Estimation of Hurdle Regression Models with an Application to Medicaid Utilization", Journal of Applied Econometrics, 12(3), 225-43.

Hansen, L.P. (1982), "Large Sample Properties of Generalized Method of Moments Estimators", Econometrica, 50(4), 1029-1054.

Hausman, J. \& B. Hall \& Z. Griliches (1984), "Economic Models for Count Data with an Application to the Patents-R\&D Relationship", Econometrica, 52, 909-938.

Hidayat, B. \& S. Pokhrel (2010), “The Selection of an Appropriate Count Data Model for Modelling Health Insurance and Health Care Demand: Case of Indonesia”, International Journal of Environmental Research and Public Health, 7, 9-27.

Hilbe, J.M. (2011), Negative Binomial Regression, Second Ed, New York: Cambridge University Press.

Jones, A. \& O. O'Donnell (2002), Econometric Analysis of Health Data, New York: John Wiley\&Sons Ltd.

Kozumi, H. (2002), "A Bayesian Analysis of Endogenous Switching Models for Count Data", Journal of the Japanese Statistical Society, 32(3), 141-154.

Kung, C.C. (2012), "Relationship between Education and Hospital Visit", International Journal of Statistics in Medical Research, 1, 51-54.

Long, J.S. (1997), Regression Models for Categorical and Limited Dependent Variables, California: Sage Publications. 
Malonzo, E.M. \& E.D. Prantilla (2007), "Count Model Estimates of Health Care Demand in Davao City", $10^{\text {th }}$ National Convention on Statistics, October 1-2, 2007, <http://www.nscb.gov.ph/ncs/10thNCS/papers/contributed\%20papers/cps-01/cps0102.pdf>, 20.02.2015.

Masuhara, H. (2008), "Semi-Nonparametric Count Data Estimation with an Endogenous Binary Variable", Economics Bulletin, 42(3), 1-13.

Mullahy, J. (1997), "Instrumental Variable Estimation of Count Data Models: Applications to Models of Cigarette Smoking Behavior", The Review of Economics and Statistics, 79(4), 586-593.

Munkin, M.K. \& P.K. Trivedi (1999), "Simulated Maximum Likelihood Estimation of Multivariate Mixed-Poisson Regression Models with Application“, Econometrics Journal, 2(1), 2948 .

Pagan, A.R. \& D. Hall (1983), "Diagnostic Tests as Residual Analysis", Econometric Reviews, 2(2), 159-218.

Pohlmeier, W. \& V. Ulrich (1995), “An Econometric Model of the Two-Part Decision Making Process in the Demand for Health Care", Journal of Human Resources, 30, 339-61.

Riphahn, R.T. \& A. Wambach \& A. Million (2003), "Incentive Effects in the Demand for Health Care: A Bivariate Panel Count Data Estimation", Journal of Applied Econometrics, 18(4), 387-405.

Romeu, A. \& M. Vera-Hernandez (2005), "Counts with an Endogenous Binary Regressor: A Series Expansion Approach", Econometrics Journal, 8(1), 1-22.

Sargan, J.D. (1975), "Testing for Misspecification after Estimating Using Instrumental Variables", Econometrica, 26(3), 393-415.

Staub, K.E. (2009), "Simple Tests for Exogeneity of a Binary Explanatory Variable in Count Data Regression Models", Socioeconomics Institute University of Zurich Working Paper, No. 0904.

Terza, J.V. \& A. Basu \& P.J. Rathouz (2008) "Two-Stage Residual Inclusion Estimation: Addressing Endogeneity in Health Econometric Modeling”, Journal of Health Economics, 27(3), 531-543.

Wang, P. \& I. Cockburn \& L. Puterman (1998), “Analysis of Patent Data-A Mixed Poisson Regression Model Approach”, Journal of Business and Economic Statistics, 16(1), 27 41.

Windmeijer, F.A.G. \& J.M.C. Santos Silva (1997), "Endogeneity in Count Data Models: An Application to Demand for Health Care", Journal of Applied Econometrics, 12(3), 281294.

Winkelmann, R. (2004), "Health Care Reform and the Number of Doctor Visits-An Econometric Analysis", Journal of Applied Econometrics, 19, 455-472.

Wooldridge, J.M. (2014), "Quasi-Maxumum Likelihood Estimation and Testing for Nonlinear Models with Endogenous Explanatory Variables”, Journal of Econometrics, 182(1), 226234.

Yaylal1, M. \& S. Kaynak \& Z. Karaca (2012), "Sağlık Hizmetleri Talebi: Erzurum İlinde Bir Araştırma”, Ege Akademik Bakış, 12 (4), 563-573.

Zimmer D. (2010), "Health Insurance and Health Care Demand Among the Selfemployed" Journal of Labor Research, 31, 1-19. 